\title{
Diagnostic characteristics of Xpert MTB/RIF assay for the diagnosis of tuberculous meningitis and rifampicin resistance in Southern Brazil
}

\author{
Características diagnósticas do Xpert MTB/RIF para o diagnóstico de \\ meningite tuberculosa e resistência à rifampicina no Sul do Brasil \\ Sergio Monteiro DE ALMEIDA',2, Gislene Maria Botão KUSSEN³, Laura COGO³, \\ José Henrique CARVALHO', Keite NOGUEIRA ${ }^{3}$
}

\begin{abstract}
Background: The timely diagnosis of tuberculous meningitis (TBM) is challenging. Molecular diagnostic tools are necessary for TBM, particularly in low- and middle-income countries. Objectives: We aimed to calculate the diagnostics characteristics of Xpert MTB/RIF for the detection of Mycobacterium tuberculosis in the cerebrospinal fluid (CSF) and the frequency of rifampicin (RIF)-resistance in the CSF samples. Methods: A total of 313 consecutive CSF samples were studied and categorized into TBM definite, probable, possible, or not TBM cases based on the clinical, laboratory, and imaging data. Results: For the definite TBM cases ( $n=7$ ), the sensitivity, specificity, efficiency, and positive likelihood ratio were 100,97, 97, and 38\%, respectively. However, for the TBM definite associated with the probable cases ( $n=24)$, the sensitivity decreased to $46 \%$. All CSF samples that were Xpert MTB/RIF-positive were RIF susceptible. Conclusion: Xpert MTB/RIF showed high discriminating value among the microbiology-proven TBM cases, although the values for the probable and possible TBM cases were reduced. Xpert MTB/RIF contributes significantly to the diagnosis of TBM, mainly when coupled with the conventional microbiological tests and clinical algorithms.
\end{abstract}

Keywords: Central Nervous System; Diagnosis; Tuberculosis, Meningeal; Polymerase Chain Reaction.

\begin{abstract}
RESUMO
Introdução: O diagnóstico da meningite tuberculosa (TBM) é desafiador. Ferramentas de diagnóstico molecular são necessárias para esse diagnóstico, particularmente em países de baixa e média renda. Objetivos: Calcular as características diagnósticas do Xpert MTB/RIF para a detecção de Mycobacterium tuberculosis no líquido cefalorraquidiano (LCR) e a frequência de resistência à rifampicina (RIF) nas amostras do LCR. Métodos: Um total de 313 amostras consecutivas de LCR foram estudadas e categorizadas em casos de TBM definida, provável, possível ou não TBM, com base nos dados clínicos, laboratoriais e de imagem. Resultados: Para os casos definidos de TBM ( $n=7)$, sensibilidade, especificidade, eficiência e razão de verossimilhança positiva foram de 100, 97, 97 e 38\%, respectivamente. No entanto, para os casos de TBM definidos associados aos prováveis ( $n=24$ ), a sensibilidade diminuiu para $46 \%$. Todas as amostras de LCR que foram positivas para Xpert MTB/RIF foram suscetiveis a RIF. Conclusão: O Xpert MTB/RIF mostrou alto valor discriminante entre os casos TBM comprovados por microbiologia, porém o valor nos casos prováveis e possiveis de TBM foram reduzidos. O Xpert MTB/RIF contribui significativamente para o diagnóstico de TBM, principalmente quando associado aos testes microbiológicos convencionais e algoritmos clínicos.
\end{abstract}

Palavras-chave: Sistema Nervoso Central; Diagnóstico; Tuberculose Meníngea; Reação em Cadeia da Polimerase.

\footnotetext{
'Universidade Federal do Paraná, Hospital de Clínicas, Ambulatório de Neuroinfecção Curitiba PR, Brazil.

¿Universidade Federal do Paraná, Hospital de Clínicas, Laboratório de virologia, Curitiba PR, Brazil.

${ }^{3}$ Universidade Federal do Paraná, Hospital de Clínicas, Laboratório de Bacteriologia, Curitiba PR, Brazil.

Sergio Monteiro DE ALMEIDA (D) https://orcid.org/0000-0001-5690-105X; Gislene Maria Botão KUSSEN (iD) https://orcid.org/0000-0003-4549-4094;

Laura COGO (D) https://orcid.org/0000-0003-0469-8883; José Henrique CARVALHO iD https://orcid.org/0000-0002-6944-9215;

Keite NOGUEIRA (ID https://orcid.org/0000-0001-5655-9645

Correpondence: Sérgio Monteiro de Almeida; E-mail: sergio.ma@ufpr.br

Conflict of interest: The authors declare no conflict of interest.

Authors contributions: All the authors participated in the concept, data collection, analysis and data interpretation, and paper writing.

Received on February 19, 2020; Received in its final form on May 18, 2020; Accepted on May 21, 2020.
} 
Central nervous system (CNS) tuberculosis (Tb) is the most severe form of $\mathrm{Tb}$, with a frequency rate of $5 \%$ as compared to $84 \%$ for pulmonary $\mathrm{Tb}$ and $11 \%$ for extrapulmonary $\mathrm{Tb}$ in the other sites ${ }^{1}$. Tb has re-emerged as a public health problem in the late 1980s because of the HIV epidemic and drug-resistant Mycobacterium tuberculosis (MTb) 2 .

The diagnosis of tuberculous meningitis (TBM) can neither be confirmed nor excluded based on the clinical features ${ }^{3}$. The early symptoms of TBM are non-specific, and diagnostic confirmation is difficult chiefly because TBM is a paucibacillary form of $\mathrm{Tb}$, so the conventional microbiological tests do not help arrive at the diagnosis. ${ }^{4}$ The identification of MTb in cerebrospinal fluid (CSF) by Ziehl-Neelsen smear microscopy is central to the diagnosis; however, its sensitivity is low, ranging from 10 to $60 \%^{5}$. In the same way, MTb culture is the reference method despite the slow-growing nature of $\mathrm{MTb}$. The time to obtaining a positive result ranges from two to eight weeks, making the culture method ineffective for rapid clinical decisions ${ }^{4}$. Facing these limitations, several nucleic acid amplification (NAA) techniques have emerged and are in regular use to overcome the inadequacies of the conventional methods of laboratory diagnosis, although the exact role of NAA tests remains uncertain ${ }^{6}$. However, no commercial polymerase chain reaction (PCR) assay for MTb has been certified for non-respiratory or paucibacillary samples, including CSF. Xpert MTB/RIF is a robust assay, with the main advantages of a shortened turnaround time and automation of the procedure that reduces hands-on time, as well as the risk of cross-contamination. The assay is robust enough to be performed outside conventional laboratories at the district and sub-district levels of the health system, but requires an uninterrupted power supply. It provides accurate results and can allow rapid initiation of multidrug-resistant tuberculosis/rifampicin-resistant tuberculosis (MDR-TB/RR-TB) treatment for cases with pending conventional culture and antimicrobial susceptibility test (AST) results?

The aims of this study were to calculate the diagnostic characteristics of Xpert MTB/RIF in CSF and the frequency of MTb rifampicin (RIF) resistance in the CSF samples. The results of the present study are expected to contribute to the findings of previous studies through further investigation of the diagnostic accuracy of Xpert MTB/RIF on a substantial number of CSF samples obtained from patients from an endemic region with suspected TBM categorized according to the international consensus case definitions ${ }^{7}$, favoring comparisons with other similar studies. The frequency of MTb RIF resistance in the CSF samples is unknown in Brazil.

\section{METHODS}

This study was approved by the Institutional Research Review Board at Hospital de Clínicas, Universidade Federal do Paraná (HC-UFPR), Curitiba, Paraná, Brazil. The authors confirmed that they have complied with the World Medical Association Declaration of Helsinki regarding the ethical conduct of research involving human subjects.

All consecutive CSF samples from patients with suspected TBM referred for NAA assay (Xpert MTB/RIF) to the Infection Disease Molecular Biology Unit (IDMBU) of HC-UFPR, between 2015 and 2019, were included in this study. All CSF samples for PCR assay were collected in DNaseand RNase-free vials to prevent degradation of the samples. During the study period, 353 CSF samples were referred to the IDMU with clinical suspicion of TBM; 40 CSF samples were excluded based on insufficient clinical data or duplicate samples. Thus, a total of 313 CSF samples were included in this study. The epidemiological data, CSF characteristics, and TBM scores ${ }^{7}$ are presented in Table 1.

\section{Tuberculous meningitis case definition and classification}

The TBM cases were categorized into definite, probable, possible, and not TBM according to the diagnostic criteria of the international consensus case definitions, which encompass clinical characteristics, CSF changes, neuroimaging criteria, and evidence of tuberculosis in the other sites? ${ }^{7}$. These data were assessed by reviewing medical records. The group classified as "not TBM" included CSF samples which were positive for infectious or non-infectious diseases or a score of $<6$. CSF standard microbiological tests were used to test samples for bacteria, fungus, or viruses ${ }^{5}$. In 60 (55\%) CSF samples, other etiologies apart from MTb were identified.

\section{GeneXpert MTB/RIF}

The MTb and RIF susceptibility were detected in uncentrifuged CSF samples by GeneXpert MTB/RIF (Cepheid, Sunnyvale, CA, USA) according to the manufacturer's recommendations. However, the GeneXpert MTB/RIF manufacturer has not claimed to use Xpert for extrapulmonary samples, including CSF. The CSF samples were processed as 300-1000 $\mu$ L aliquots.

\section{Cerebrospinal fluid microbiological testing for M. tuberculosis}

The CSF sediment, after concentration by centrifugation, was used to prepare smears for direct examination of acid-fast bacilli (AFB) using Ziehl-Gabbett cold staining. The CSF culture for M. tuberculosis was inoculated onto Löwenstein-Jensen solid medium culture plates, incubated at $37^{\circ} \mathrm{C}$, and observed biweekly for two months. The isolates of $M$. tuberculosis were identified, and antimicrobial susceptibility testing was performed using the BD MGIT 320 system (Becton Dickinson, New Jersey, EUA) according to the manufacturer's recommendations.

\section{Statistical analyses}

The diagnostic characteristics of the Xpert MTB/RIF (index test) in CSF for TBM were calculated using positive CSF 
Table 1. Epidemiological, cytological, and biochemical characteristics of cerebrospinal fluid of all groups studied.

\begin{tabular}{|c|c|c|c|c|c|}
\hline & Definite & Probable & Possible & Not TBM & $p$-value ${ }^{b}$ \\
\hline $\mathrm{n}$ & 7 & 17 & 179 & 110 & \\
\hline Age, years & $52(40 ; 53.50)$ & $45(35.50 ; 54)$ & $46(33 ; 59)$ & $42(30.50 ; 53.50)$ & 0.542 \\
\hline Male, n (\%) & $4(57.14)$ & $9(52.94)$ & $105(58.66)$ & $58(52.73)$ & 0.788 \\
\hline $\mathrm{HIV}+, \mathrm{n}(\%)$ & $4(57.14)$ & $9 / 15(60)$ & $70 / 169(41.42)$ & 49/104 (47.12) & 0.417 \\
\hline \multicolumn{6}{|l|}{ CSF } \\
\hline WBC, $\times 10^{6} / \mathrm{L}$ & $226(35 ; 605)$ & $8.20(1.00 ; 39.75)$ & $1.80(0.60 ; 5.15)$ & $2.50(22.35 ; 0.90)$ & $<0.001$ \\
\hline$W B C>5 \times 10^{6} / L, n(\%)$ & $7(100)$ & $11(64.71)$ & $44(24.58)$ & $41(37.27)$ & $<0.001$ \\
\hline Lymphocytes \% & $76.00(39.50 ; 94.00)$ & $86.00(64.50 ; 96.50)$ & $90(36.5 ; 97.00)$ & $91.00(82.5 ; 97)$ & 0.313 \\
\hline Predominant lymphocytes, n (\%) & $4(57)$ & $10 / 10(100)$ & $34 / 46(74)$ & $33 / 40(83)$ & 0.132 \\
\hline $\mathrm{RBC}, \times 10^{6} / \mathrm{L}$ & $6.00(5.45 ; 417.5)$ & $1.72(13.80 ; 0.30)$ & $7.20(1.00 ; 107.3)$ & $5.60(0.90 ; 86.55)$ & 0.189 \\
\hline $\mathrm{TP}, \mathrm{g} / \mathrm{L}$ & $1.61(0.97 ; 4.01)$ & $1.00(0.32 ; 1.74)$ & $0.45(0.31 ; 0.70)$ & $0.58(0.34 ; 1.14)$ & $<0.001$ \\
\hline $\mathrm{TP}>0.45 \mathrm{~g} / \mathrm{L}, \mathrm{n}(\%)$ & $7(100)$ & $11(64.71)$ & $86 / 175(49.14)$ & $73(66.36)$ & 0.003 \\
\hline $\mathrm{GL}, \mathrm{mmol} / \mathrm{L}$ & $0.78(0.42 ; 1.78)$ & $2.66(2.05 ; 4.19)$ & $3.16(2.61 ; 3.86)$ & $2.86(2.28 ; 3.47)$ & $<0.001$ \\
\hline $\mathrm{GL} \leq 2.2 \mathrm{mmol} / \mathrm{L}, \mathrm{n}(\%)$ & $7(100)$ & $5(29.41)$ & $26 / 178(14.61)$ & $26(23.64)$ & 0.001 \\
\hline GL CSF/serum & $0.136(0.041 ; 0.220)$ & $0.462(0.386 ; 0.687)$ & $0.592(0.468 ; 0.734)$ & $0.449(0.0 ; 0.622)$ & $<0.001$ \\
\hline Culture MTba, n (\%) & $6(86)$ & 0 & 0 & 0 & \\
\hline AFB smeara, $\mathrm{n}(\%)$ & $1(14)$ & 0 & 0 & 0 & \\
\hline GeneXpert MTB/RIFa, n (\%) & $7(100)$ & $4(23.53)$ & $2(1.12)$ & $2(1.82)$ & $<0.001$ \\
\hline
\end{tabular}

Data was showed in median (IQR) or number (\%) as appropriate. CSF: cerebrospinal fluid; WBC: white blood cells; RBC: red blood cells; TP: total proteins; GL: glucose; LA: lactic acid; TBM: tuberculous meningitis; MTb: Mycobacterium tuberculosis. Screening for acid-fast bacilli (AFB) was performed by CSF smear microscopy.

CSF biochemistry and cytology were quantified following standard methods ${ }^{5}$. ${ }^{a}$ : number (\%) of positive cases; ${ }^{\text {b: }}$ comparison between the four groups by chisquare test.

acid-fast bacilli culture-proven (definite TBM) and/or probable $\mathrm{TBM}^{7}$ as the reference method. The following diagnostic characteristics were calculated: sensitivity, specificity, accuracy (efficiency or test score), positive predictive value (PPV), negative predictive value (NPV), Youden's index (J), error rate $=$ ( false positive+false negative)/true positive, false positive rate, presumptive positive, detection rate, error rate, and combined error'. The clinical utility index positive and negative (CUI+, CUI-) was classified as follows: utility excellent, $\geq 0.81$; good, $\geq 0.64$; fair, $\geq 0.49$; poor, $\leq 0.49$; and very poor, $\leq 0.36^{10,11}$. The positive and negative likelihood ratio (LR+, LR-) $)^{12,13}$ and diagnostic odds ratio (DOR=LR+/LR-) were also calculated. An LR+ of around $\geq 10.0$ indicated that a positive test almost confirmed the disease, a value of around 6.0 indicated that the disease was present, and a value of around 1.0 indicated that the test was unable to show whether the disease was present or not. An $\mathrm{LR}+$ around $\leq 0.1$ indicated that the disease was practically absent $^{12,13}$. The receiver operating characteristic (ROC) curve was constructed using SPSS version 22 (IBM Corp., Armonk, NY, USA $)^{12,14}$. The post-test probability for a positive and a negative test was calculated using the Fagan nomogram ${ }^{15,16}$.

The concordance between the CSF culture and Xpert MTB/RIF was determined by the kappa statistics (K): complete agreement, $\mathrm{K}=1$, and lack of agreement (i.e., purely random coincidences of rates), $\mathrm{K}=0$. The categorical variables were compared among the groups using the chi-square test, and the continuous variables were compared using the Mann-Whitney or Kruskal-Wallis test for non-parametric data, as appropriate. The results were considered significant at the $5 \%$ alpha level.

\section{RESULTS}

The Standards for Reporting of Diagnostic Accuracy Studies diagram of the flow of participants through the study is shown in Figure 1. The epidemiological, CSF cytological, and biochemical characteristics of all the groups studied are shown in Table 1. The categorized TBM groups were comparable in terms of age and sex.

Xpert MTB/RIF was positive in 15 (4.79\%) of all 313 CSF samples. The concordance between the CSF culture and Xpert MTB/RIF was moderate, $\mathrm{K}=0.559$ (SD: 0.145 ; $95 \%$ confidence interval [95\%CI] $0.276-0.843)$. The identification of AFB by direct microscopy was positive in one case, and the concordance between CSF direct examination and Xpert MTB/RIF was poor with a K of 0.120 (SD: 0.230; 95\%CI $(-0.331)-(0.570))$.

The positivity rates of Xpert MTB/RIF in CSF in the different groups categorized according to TBM diagnosis are shown in Figure 2. The positivity rates of the four groups were 


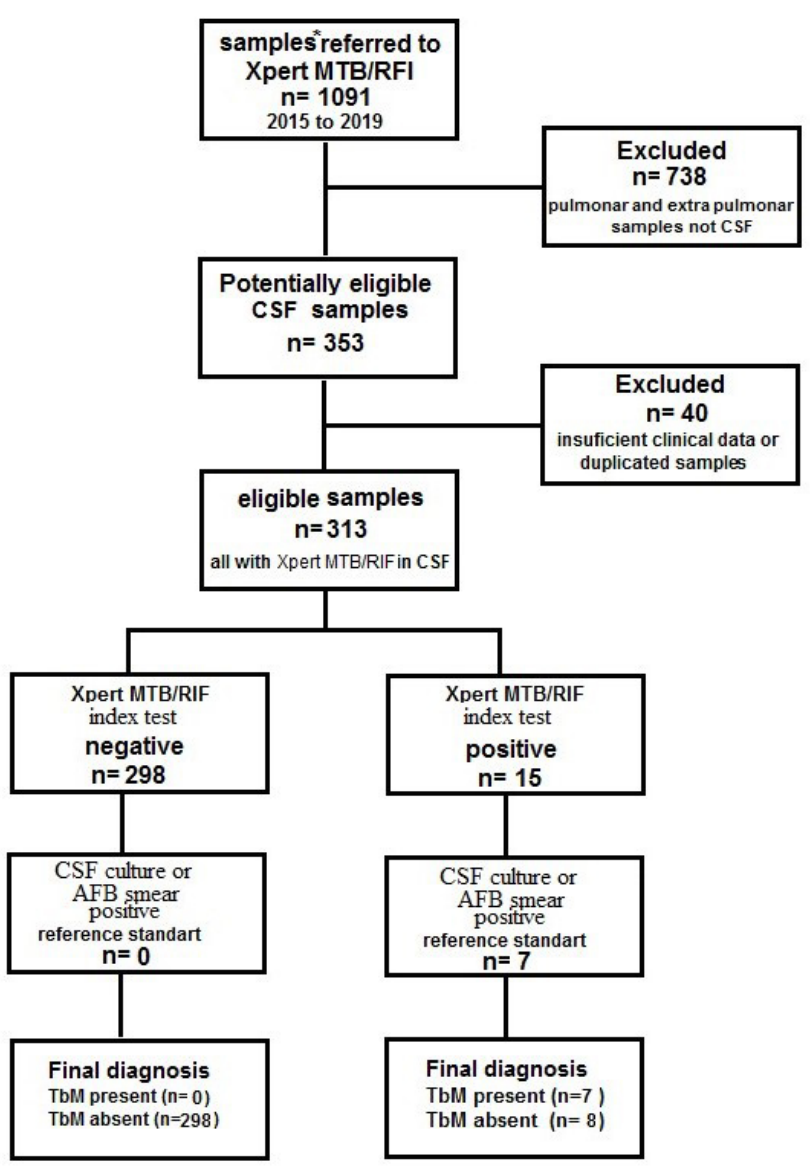

*All samples from HC-UFPR inpatients referred to the Infection Disease Molecular Biology Unit (IDMBU) of HC-UFPR, Brazil.

CSF: cerebrospinal fluid; AFB: acid-fast bacilli; TBM: tuberculous meningitis. Figure 1. Standards for Reporting of Diagnostic Accuracy Studies diagram of the flow of participants through the validation of Xpert MTB/RIF (index test) for the diagnosis of tuberculous meningitis in cerebrospinal fluid samples. The reference standard was cerebrospinal fluid culture for Mycobacteriumtuberculosis inoculated onto a solid medium.

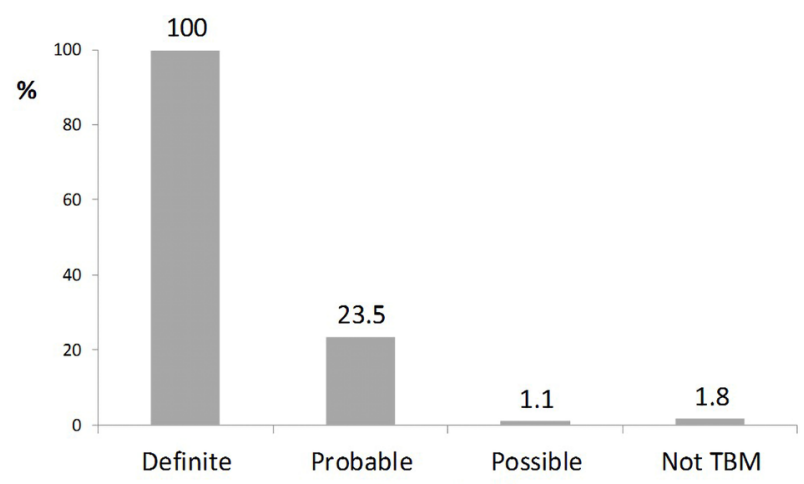

TB meningitis

$\mathbf{P}<0.0001$

TBM: tuberculous meningitis.

Figure 2. Positivity rate of GeneXpert MTB/RIF in the cerebrospinal fluid for the diagnosis of $M$. tuberculosis meningitis in the different categorized groups ( $p<0.001$ as compared to the four groups). significantly different $(\mathrm{p}<0.001)$. Xpert MTB/RIF was positive in two cases in the not TBM cases, one of those was RIF susceptible with a diagnosis of CNS lymphoma (mantle cell lymphoma). In this study, it was considered a false positive result; however, this could be due to the association of lymphoma with TBM.

The diagnostic characteristics of Xpert MTB/RIF in the different clinically categorized TBM groups are shown in Table 2 and Figure 3. Among the microbiology-proven cases of TBM (definite TBM; $n=7$ ), the sensitivity of Xpert MTB/RIF in CSF was very high (100\%), signifying that a positive result is often seen in patients with the disease having CSF-positive MTb culture or smear. The specificity of the test was high (97.39\%), i.e., a negative result was often seen in patients without the condition. The PPV of the test was low, implying false positives were common in patients who screen positive, thereby limiting the value of the test for case definition. The NPV was very high, i.e., false negatives were rare in patients who screen negative, thereby suggesting a potentially useful screening test. Hence, the CUI+ of the test for case-findings (confirmation) was poor, and the CUI of the test for screening (ruling out) was excellent. The overall value

Table 2. Diagnostic characteristics of GeneXpert MTB/RIF in cerebrospinal fluid for the diagnosis of tuberculous meningitis in the different groups.

\begin{tabular}{lccc}
\hline & Definite & $\begin{array}{c}\text { Definite }+ \\
\text { Probable }\end{array}$ & $\begin{array}{c}\text { Definite }+ \\
\text { Probable }+ \\
\text { Possible }\end{array}$ \\
\hline$n$ & 7 & 24 & 203 \\
\hline Prevalence (\%) & 2.24 & 7.67 & - \\
\hline TP (n) & 7 & 11 & 13 \\
\hline Sensibility (\%) & 100 & 45.83 & 6.40 \\
\hline Specificity (\%) & 97.39 & 98.62 & 98.18 \\
\hline PPV (\%) & 46.67 & 73.33 & 86.67 \\
\hline NPV (\%) & 100 & 95.64 & 36.24 \\
\hline Eficiency (test score) (\%) & 97.44 & 94.57 & 38.66 \\
\hline Youden Index & 0.974 & 0.445 & 0.046 \\
\hline False + rate (\%) & 53.33 & 26.67 & 13.33 \\
\hline Detection rate (\%) & 2.24 & 3.51 & 4.15 \\
\hline Error rate & 114 & 155 & 1477 \\
\hline Combined error & 2.56 & 5.43 & 61.34 \\
\hline LR+ & 38.25 & 33.11 & 3.52 \\
\hline LR- & 0 & 0.55 & 0.95 \\
\hline DOR & 517 & 60.2 & 3.71 \\
\hline Clinical utility+ & Poor 0.467 & Poor 0.336 & V Poor \\
\hline Clinical utility- & Excellent & Excellent & V Poor \\
\hline CT: threshold & 0.943 & 0.356 \\
\hline
\end{tabular}

CT: threshold cycle; TP: true positive; PPV: positive predictive value; NPV: negative predictive value; LR+: positive likelihood; LR-: negative likelihood; DOR: diagnostic odds ratio. 


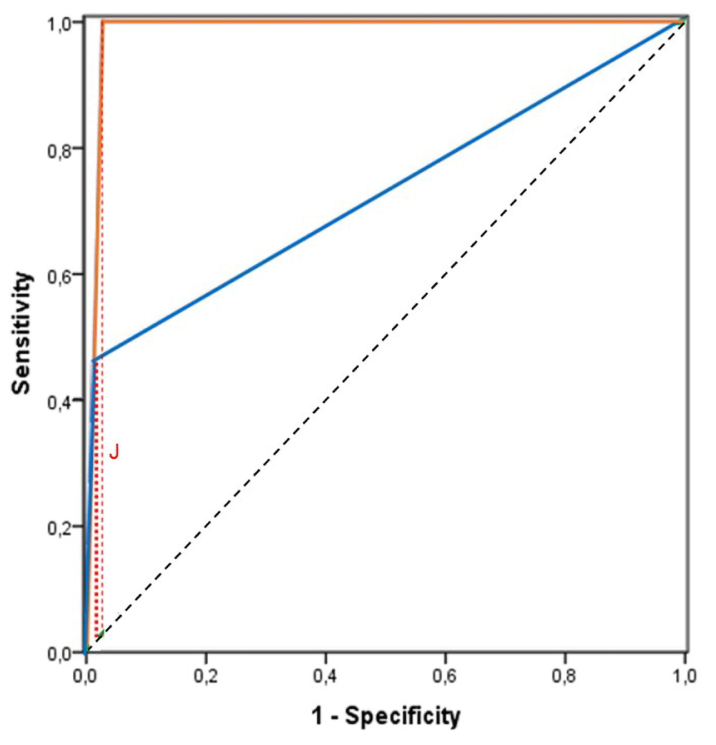

ROC curve of the group with definite Tb meningitis (microbiology-proven, brown line), area under the curve (AUC) $=0.987$ (95\% $\mathrm{Cl} 0.98-1.0)$; for definite or probable Tb meningitis (blue line), AUC=0.722 (95\% Cl 0.59-0.85). The Youden's index $(\mathrm{J})$ is shown by the red dashed lines

Figure 3. Receiver operating characteristic (ROC) curve of Xpert MTB/RIF in cerebrospinal fluid samples for diagnosis of tuberculous meningitis categorized as definite and probable. of this single test for combined screening and case finding showed a good score of 97.4 (out of 100). Considering definite associated with probable TBM cases $(n=24)$, the sensitivity of Xpert MTB/RIF in CSF was low (45.83\%), meaning a positive result was not seen in those with a disease. The specificity of the test was high (98.62\%). The PPV of the test was modest, implying false positives are a little common in those who screen positive. The NPV was rather very high. Hence, the CUI of the test for case-finding (confirmation) was very poor, and the CUI of the test for screening (ruling out) was excellent. The overall value of this single test for combined screening and case finding showed a fair score of 94.6 (out of 100). Although considering the definite, probable and possible TBM cases, the sensitivity of Xpert MTB/RIF in CSF was extremely low, and the specificity was high. The overall value of this single test for combined screening and case finding was very poor with a score of 38.7 (out of 100). In the Fagan nomogram analysis of the definite TBM scenario, the posttest probability of a positive test result was $47 \%$, while for definite or probable TBM a positive posterior probability of $73 \%$ could be considered to diagnose $\mathrm{Tb}$, and the post-test probability was $4 \%$ for a negative test result (Figure 4).

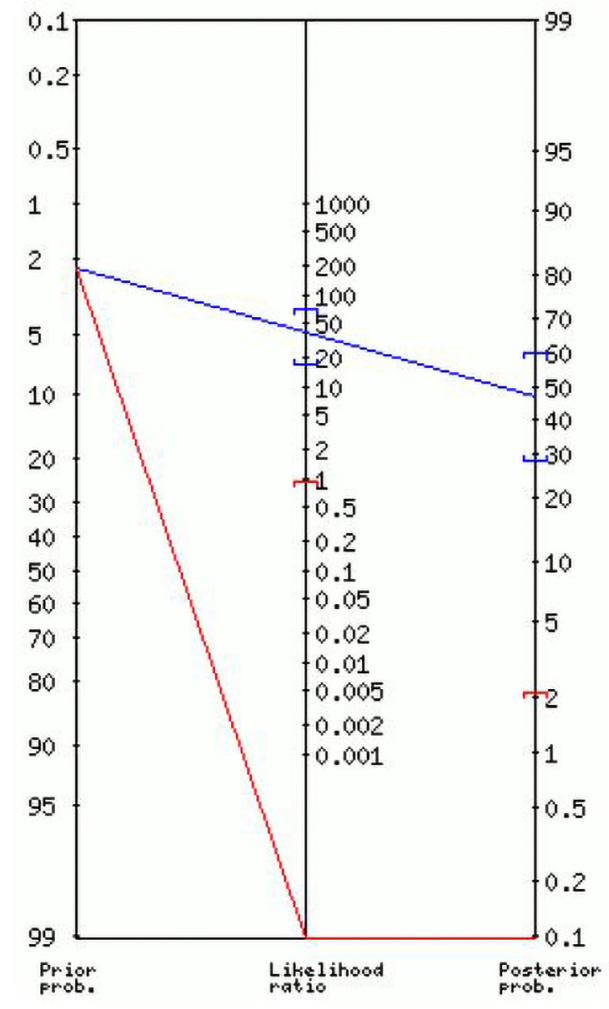

a.

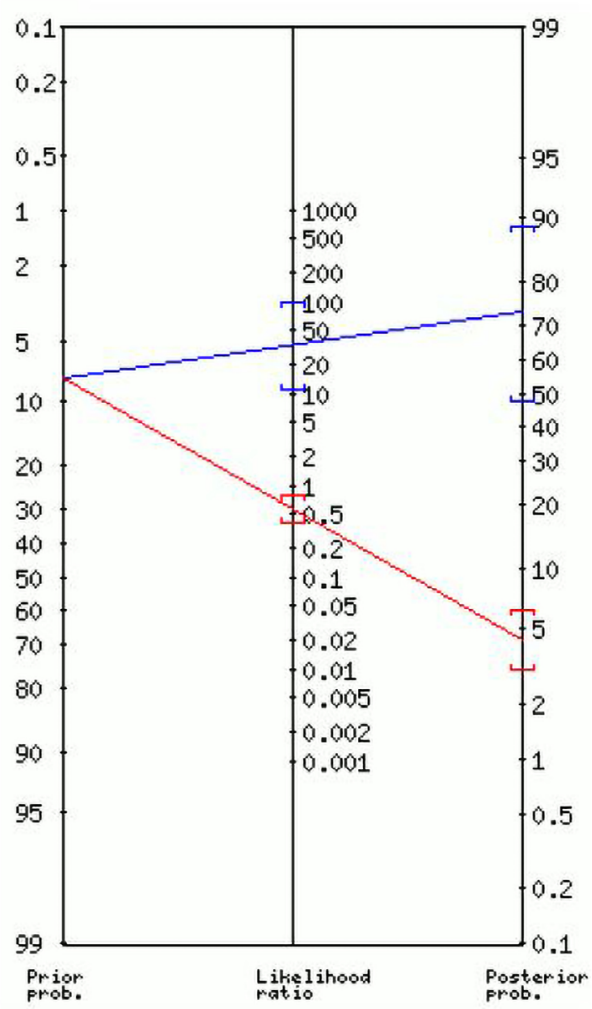

b.

Odds: Probability/(1-Probability); Posterior odds: Prior odds $\times$ LR; LR: Likelihood ratio.

a. For the group with definite TBM, the prior probability (odds) was 2.24\% (0.0). For a positive test (blue line): LR+ 38 (95\%Cl 17-67); Posterior probability (odds): $47 \%(0.9)(95 \% \mathrm{Cl} 28-61)$; around 1 in 2.2 with positive test had TBM. For a negative test (red line): LR- 0.00 (95\%Cl 0.00-0.94); Posterior probability (odds): 0\% (0.0) $(95 \% \mathrm{Cl} 0-2)$; around 1 in 1.0 with negative test were not sick. b. For the group with definite or probable TBM, the prior probability (odds) was $7.67 \%(0.1)$. For a positive test (blue line): LR+ 33 (95\% Cl 11-96); posterior probability (odds): $73 \%$ (2.7) (95\% Cl 48-89); around 1 in 1.4 with positive test had TBM. For a negative test (red line): LR- 0.55 (95\% Cl 0.38-0.79); Posterior probability (odds): $4 \%(0.0)(95 \% \mathrm{Cl} 3-6)$; around 1 in 1.0 with negative test were not sick.

Figure 4. Fagan's nomogram showing posterior probability for positive or negative results in Xpert MTB/RIF in the cerebrospinal fluid. 


\section{Rifampicin resistance}

Eleven cases with Xpert MTB/RIF positive were RIF susceptible, of these five were in concordance with the M. tuberculosis AST, which is the gold standard ${ }^{17}$. In four cases, the RIF susceptibility by the Xpert MTB/RIF was not reported.

\section{DISCUSSION}

The exact role of NAA tests for TBM diagnosis in the CSF sample remains uncertain, although several meta-analyses have been published ${ }^{6,18,19}$. The different case definitions and the different reference standard tests used in studies make comparisons of research findings difficult ${ }^{6}$.

Our data showed, among the microbiology definite TBM, the sensitivity and specificity of the Xpert MTB/RIF in CSF were very high. The overall value of Xpert MTB/RIF for combined screening and case finding was good. Perhaps considering the association of cases with definite or probable TBM, the diagnostic capacity of Xpert MTB/RIF reduced considerably. It accurately identified only $46 \%$ of all clinically defined cases, although identified correctly $99 \%$ of those who did not have TBM. The area under the ROC curve (AUC) reflects the diagnostic value in distinguishing between patients with the disease and those without ${ }^{14}$. In the present study, MTb Xpert showed a high discriminating value among the microbiology-proven TBM cases, thereby reducing the value among the probable and possible TBM cases. These diagnostic characteristics for definitive and probable TBM were similar to those described previously $y^{6,20,21}$.

The low prevalence (5.4\%) of the positive Xpert MTB/RIF results identified in this study is similar to those reported previously ${ }^{22,23}$. These findings reveal the low pretest probability of disease using Xpert MTB/RIF in routine practice and highlight the need to implement algorithms to optimize the test requested ${ }^{23}$. This is particularly important in scenarios with limited resources in which shortages are a constant concern. The possible reason for the limited sensitivity of Xpert MTB/RIF could be the low CSF volume (mostly the laboratory received $<1 \mathrm{~mL}$ of CSF specimens) referred to the IDMBU to perform the assay, although the impact of CSF volume was not evaluated in this study. The other reason could be the presence of inhibitory factors previously documented in the CSF samples, such as the presence of red blood cells (RBC) or proteins ${ }^{24,25,26}$, although the literature on this subject is scarce. Traumatic CSF punctures are frequent in clinical practice, and the Xpert MTB/RIF was not validated for blood samples. However, a previous study with real-time PCR for the detection of $M$. tuberculosis (MTb qPCR) in the CSF showed that the number of RBC in the CSF did not inhibit the MTb qPCR ${ }^{27}$.

In 2013, the World Health Organization (WHO) recommended that Xpert should be used in place of conventional microscopy and culture as the first diagnostic test in CSF samples in patients with suspected $\mathrm{TBM}^{19,28}$ irrespective of the fact that its sensitivity varied widely in the included studies $^{18}$. Although the Xpert manufacturer has not recommended the use Xpert for samples other than sputum, several studies have been conducted to evaluate the utility of Xpert in the diagnosis of extrapulmonary TB, including $\mathrm{TBM}^{19}$. Therefore, although Xpert could be useful in patients with TBM, a negative result does not exclude the possibility ${ }^{28}$.

All CSF samples with Xpert MTB/RIF-positive were RIF susceptible; in five of these cases, the drug susceptibility was confirmed by CSF culture and DST. The bacteriological evidence served as the gold standard for the detection of MDR-TB/RR-TB ${ }^{17}$. To the best of our knowledge, the susceptibility of MTb to RIF in CSF samples has not been reported earlier in Brazil, however the number of samples studied was small for a definite conclusion, warranting further studies. Xpert detects the MTb rpoB gene and allows to detect mutations that may confer resistance to rifampicin ${ }^{29,30}$. MDR-TB/RR-TB is emerging as a major problem due to poor management of drug-sensitive, as well as drug-resistant $\mathrm{Tb}^{17}$. MDR-TB/RR-TB has been an area of growing concern to human health worldwide and posing a threat to the control of $\mathrm{Tb}$. The Global $\mathrm{Tb}$ Report 2016 estimated that of the 3.9\% newly diagnosed $\mathrm{Tb}$ cases, $21 \%$ of previously treated $\mathrm{Tb}$ cases had MDR-TB ${ }^{17}$. In India, the prevalence of MDR M. tuberculosis was $5.6 \%$ in TBM patients ${ }^{31}$. In Brazil, the M. tuberculosis primary resistance to RIF (in patients that never received tuberculosis treatment, i.e. infected with MTb previously resistant to treatment) in sputum samples was $0.6 \%$ and the acquired resistance (in patients previously with MTb initially sensible, who turned resistant after the exposition to treatment) was $2.5 \%$, combined resistance was $1.0 \%^{32,33}$.

Other methodologies have now been developed for MTb diagnosis, such as Xpert MTB/RIF Ultra (Cepheid, Inc., Sunnyvale, CA, USA), which have appealed as new diagnostic tools, although they have not been yet validated for CSF and tend to show several limitations when used in CSF samples $^{34,35,36,37}$. The use of GeneXpert MTB/RIF Ultra for TBM diagnosis was also endorsed by the WHO in the 2017, due to its high sensitivity, especially in patients with HIV co-infec$\operatorname{tion}^{38}$. Hence, further studies are necessary to establish the real diagnostic accuracy of these tests in CSF. In addition, a comparison of the results among different methods would be useful. Several low- and middle-income countries, which are precisely the countries with a higher $\mathrm{Tb}$ prevalence, do not have access to these robust technology methods, highlighting the need to validate the efficiency of more accessible NAA tests in evaluating CSF.

The strength of this study is that the authors included all CSF samples evaluated by Xpert MTB/RIF within the study period in a sequential manner. For the first time, MTb RIF susceptibility to TBM CSF samples was studied in an area endemic for MTb in Brazil, especially the Southern parts. The main limitations are its retrospective design and the 
small number of CSF samples that were MTb culture-positive. Considering the association of definite and probable TBM, the number of cases in this study was similar to that reported in other studies ${ }^{34,35}$. The CSF samples of definite TBM are rare due to the difficulty to detect MTb in the CSF. In our study, the rate of CSF culture positivity for MTb was 29\%; considering the groups with definite and probable TBM, this result was in accordance with that of the previous studies $^{27,39,40}$. TBM accounts for $5 \%$ of all $\mathrm{Tb}$ cases; among which, $1.25 \%$ account for culture-proven TBM cases. This explains the low number of definite cases in the present study and the difficulty in conducting studies on the diagnosis and treatment of TBM ${ }^{1}$.

The analytical sensitivity of molecular biology methods is higher than that of the traditional culture methods (reference method). This is an intrinsic characteristic of molecular biology methods, and it is difficult to analyze the diagnostics characteristics of these new technologies. Because of these, it is suggested to add clinical criteria as a reference method with the use of molecular biology methods.

Commercial NAA tests generally show high specificities and can, therefore, be used to establish a definitive diagnosis in patients with symptoms or signs suggestive of TBM. However, more data are urgently needed to establish the robustness of these tests in field conditions; the specificities of both culture and PCR methods might be compromised in areas endemic for tuberculosis because of an increased risk of sample cross-contamination. The specificity of TBM diagnosis can be improved by molecular diagnostics tests ${ }^{7}$. Our data support the Xpert MTB/RIF assay for TBM diagnosis using CSF samples. It has the potential for use in clinical settings. In particular, in patients with positive TBM clinical scores, Xpert MTB/RIF should be used as an adjunct to conventional microbiological tests and clinical algorithms.

\section{References}

1. Wilder-Smith EP. Mycobacterium tuberculosis. In: Lisak RP, Truong DD, Carroll WM, Bhidayasiri R, editors. International neurology, a clinical approach. Oxford (UK): Blackwell Publishing; 2009. p.258-61.

2. World Health Organization. Resolution WHA62.15. Prevention and control of multidrug-resistant tuberculosis and extensively drug-resistant tuberculosis. In: Sixty-second World Health Assembly, Geneva, 18-22 May 2009. Resolutions and decisions; annexes. Geneva: World Health Organization; 2009. (WHA62/2009/ $\mathrm{REC} / 1): 25-9$

3. Roca B, Tornador N, Tornador E. Presentation and outcome of tuberculous meningitis in adults in the province of Castellon, Spain: a retrospective study. Epidemiol Infect. 2008 Nov;136(11):1455-62. https://doi.org/10.1017/S0950268807000258

4. Thakur R, Goyal R, Sarma S. laboratory diagnosis of tuberculous meningitis - is there a scope for further improvement? $\mathrm{J} \mathrm{Lab}$ Physicians. 2010 Jan;2(1):21-4. https://doi.org/10.4103/09742727.66705

5. Fishman RA. Cerebrospinal fluid in diseases of the nervous system. 2. ed. Philadelphia:WB Saunders; 1992.

6. Pormohammad A, Nasiri MJ, Mchugh TD, Riahi SE, Bahre NC. A systematic review and meta-analysis of the diagnostic accuracy of nucleic acid amplification tests for tuberculous meningitis. $J$ Clin Microbiol. 2019 Jun;57(6):e01113-18. https://doi.org/10.1128/ JCM.01113-18

7. Marais S, Thwaites G, Schoeman JF, Török ME, Misra UK, Prasad K, et al. Tuberculous meningitis: a uniform case definition for use in clinical research. Lancet Infect Dis. 2010 Nov; 10(11):803-12. https:// doi.org/10.1016/S1473-3099(10)70138-9

8. Kent PT. Public health mycobacteriology: a guide for the level III laboratory. Atlanta: Centers for Disease Control; 1985.

9. Galen RS, Gambino SR. Beyond normality, the predictive value and efficiency of medical diagnoses. New York: Wiley \& Sons; 1975.

10. Mitchell AJ. The clinical significance of subjective memory complaints in the diagnosis of mild cognitive impairment and dementia: a meta-analysis. Int J Geriatr Psychiatry. 2008 Nov;23(11):1191-202. https://doi.org/10.1002/gps.2053

11. Mitchell AJ. Sensitivity $\times$ PPV is a recognized test called the clinical utility index (CUI+). Eur J Epidemiol. 2011 Mar;26(3):251-2;author reply 252. https://doi.org/10.1007/s10654-011-9561-x
12. Akobeng AK. Understanding diagnostic tests 2: likelihood ratios, pre- and post-test probabilities and their use in clinical practice. Acta Paediatr. 2007 Apr;96(4):487-91. https://doi.org/10.1111/j.16512227.2006.00179.x

13. McGee S. Simplifying likelihood ratios.J Gen Intern Med. 2002 Aug;17(8):646-9. https://doi.org/10.1046/j.1525-1497.2002.10750.x

14. Akobeng AK. Understanding diagnostic tests 3: receiver operating characteristic curves. Acta Paediatr. 2007 May;96(5):644-7. https:// doi.org/10.1111/j.1651-2227.2006.00178.x

15. Sackett DL, Haynes RB. The architecture of diagnostic research. BMJ. 2002 Mar;324(7336):539-41. https://doi.org/10.1136/ bmj.324.7336.539

16. Fagan TJ. Letter: nomogram for Bayes theorem. N Engl J Med. 1975 Jul;293(5):257. https://doi.org/10.1056/NEJM197507312930513

17. Prasad R, Gupta N, Banka A. Multidrug-resistant tuberculosis/ rifampicin-resistant tuberculosis: Principles of management. Lung India. 2018 Jan-Feb;35(1):78-81. https://doi.org/10.4103/lungindia. lungindia_98_17

18. Denkinger CM, Schumacher SG, Boehme CC, Dendukuri N, Pai M, Steingart KR. Xpert MTB/RIF assay for the diagnosis of extrapulmonary tuberculosis: a systematic review and metaanalysis Eur Respir J. 2014 Aug;44(2):435-46. https://doi. org/10.1183/09031936.00007814

19. Kohli M, Schiller I, Dendukuri N, Dheda K, Denkinger CM, Schumacher SG, et al. Xpert ${ }^{\circledR}$ MTB/RIF assay for extrapulmonary tuberculosis and rifampicin resistance. Cochrane Database Syst Rev. 2018 Aug;8(8):CD012768. https://doi.org/10.1002/14651858. CD012768.pub2

20. Wilkinson RJ, Rohlwink U, Misra UK, van Crevel R, Mai NTH, Dooley KE, et al. Tuberculous meningitis. Nat Rev Neurol. 2017 Oct;13(10):581-98. https://doi.org/10.1038/nrneurol.2017.120

21. Allahyartorkaman M, Mirsaeidi M, Hamzehloo G, Amini S, Zakiloo M, Nasiri MJ. Low diagnostic accuracy of Xpert MTB/RIF assay for extrapulmonary tuberculosis: a multicenter surveillance. Sci Rep. 2019 Dec;9(1):18515. https://doi.org/10.1038/s41598-019-55112-y

22. Pink F, Brown TJ, Kranzer K, Drobniewski. F Evaluation of Xpert MTB/ RIF for detection of Mycobacterium tuberculosis in cerebrospinal fluid. J Clin Microbiol. 2016 Mar;54(3):809-11. https://doi. org/10.1128/JCM.02806-15 
23. Azevedo RG, Dinallo FS, de Laurentis LS, Boulware DR, Vidal JE. Xpert MTB/RIF ${ }^{\circledast}$ assay for the diagnosis of HIV-related tuberculous meningitis in São Paulo, Brazil. Int J Tuberc Lung Dis. 2018 Jun;22(6):706-7. https://doi.org/10.5588/ijtld.18.0191

24. Ratnamohan VM, Cunningham AL, Rawlinson WD. Removal of inhibitors of CSF-PCR to improve diagnosis of herpesviral encephalitis. J Virol Methods. 1998 May;72(1):59-65. https://doi.org/10.1016/s01660934(98)00020-2

25. Almeida SM, Raboni SM, Noqueira MB, Vidal LRR. Red blood cells in cerebrospinal fluid as possible inhibitory factor for enterovirus RT-PCR. Arq Neuro-Psiquiatr. 2016 Oct;74(10):810-5. https://doi. org/10.1590/0004-282X20160119

26. Lee CK, Chai CN, Capinpin SM, Ang A, Ng SY, Lee PL, et al. Evaluation of the Luminex ARIES HSV 1 and 2 Assay and comparison with the FTD Neuro 9 and In-house Real-Time PCR Assays for detecting Herpes Simplex Viruses. Ann Lab Med. 2018 Sep;38(5):440-5. https:// doi.org/10.3343/alm.2018.38.5.440

27. de Almeida SM, Borges CM, Santana LB, Golin G, Correa L, Kussen GB, et al. Validation of Mycobacterium tuberculosis realtime polymerase chain reaction for diagnosis of tuberculous meningitis using cerebrospinal fluid samples: a pilot study. Clin Chem Lab Med. 2019 Mar;57(4):556-64. https://doi.org/10.1515/ cclm-2018-0524

28. Méchaï F, Bouchaud O. Tuberculous meningitis: challenges in diagnosis and management. Rev Neurol (Paris). 2019 SepOct;175(7-8):451-7. https://doi.org/10.1016/j.neurol.2019.07.007

29. Kay AW, Fernández LG, Takwoingi Y, Eisenhut M, Detjen AK, Steingart KR, et al. Xpert MTB/RIF and Xpert MTB/RIF Ultra assays for active tuberculosis and rifampicin resistance in children. Cochrane Database Syst Rev. 2020 Aug;8:CD013359. https://doi. org/10.1002/14651858.CD013359.pub2

30. Sharma K, Sharma M, Chaudhary L, Modi M, Goyal M, Sharma $\mathrm{N}$, et al. Comparative evaluation of Xpert MTB/RIF assay with multiplex polymerase chain reaction for the diagnosis of tuberculous meningitis. Tuberculosis (Edinb). 2018 Dec;113:38-42. https://doi. org/10.1016/j.tube.2018.09.002

31. Gupta R, Thakur R, Kushwaha S, Jalan N, Rawat P, Gupta P, et al. Isoniazid and rifampicin heteroresistant Mycobacterium tuberculosis isolated from tuberculous meningitis patients in India. Indian J Tuberc. 2018 Jan;65(1):52-6. https://doi.org/10.1016/j. ijtb.2017.08.005
32. Micheletti VCD, Moreira JS, Ribeiro MO, Kritski AL, Braga JU. Drugresistant tuberculosis in subjects included in the Second National Survey on Antituberculosis Drug Resistance in Porto Alegre, Brazil.J Bras Pneumol. 2014 Mar-Apr;40(2):155-63. https://doi.org/10.1590/ S1806-37132014000200009

33. Marques M, Cunha EAT, Evangelista MSN, Basta PC, Marques AMC, Croda J, et al. Resistência às drogas antituberculose na fronteira do Brasil com Paraguai e Bolívia. Rev Panam Salud Publica. 2017 Jan;41:e9. https://doi.org/10.26633/RPSP.2017.9

34. Bahr NC, Marais S, Caws M, van Crevel R, Wilkinson RJ, Tyagi JS, et al. GeneXpert MTB/Rif to diagnose tuberculous meningitis: perhaps the first test but not the last. Clin Infect Dis. 2016 May;62(9):1133-5. https://doi.org/10.1093/cid/ciw083

35. Bahr NC, Nuwagira E, Evans EE, Cresswell FV, Bystrom PV, Byamukama A, et al. Diagnostic accuracy of Xpert MTB/RIF Ultra for tuberculous meningitis in HIV-infected adults: a prospective cohort study. Lancet Infect Dis. 2018 Jan;18(1):68-75. https://doi. org/10.1016/S1473-3099(17)30474-7

36. Zhang M, Xue M, He JQ. Diagnostic accuracy of the new Xpert MTB/ RIF Ultra for tuberculosis disease: a preliminary systematic review and meta-analysis. Int J Infect Dis. 2020 Jan;90:35-45. https://doi. org/10.1016/j.ijid.2019.09.016

37. Chin JH, Musubire AK, Morgan N, Pellinen J, Grossman S, Bhatt $\mathrm{JM}$, et al. Xpert MTB/RIF Ultra for detection of mycobacterium tuberculosis in cerebrospinal fluid. J Clin Microbiol. 2019 Jun;57(6):e00249-19. https://doi.org/10.1128/JCM.00249-19

38. WHO meeting report of a technical expert consultation: noninferiority analysis of Xpert MTF/RIF Ultra compared to Xpert MTB/RIF. Geneva: World Health Organization; 2017 (WHO/ HTM/TB/2017.04). Available from: https://apps.who.int/iris/ bitstream/handle/10665/254792/WHO-HTM-TB-2017.04-eng. pdf? sequence $=1$ \&isAllowed $=y$

39. Chiang SS, Khan FA, Milstein MB, Tolman AW, Benedetti A, Starke JR, et al. Treatment outcomes of childhood tuberculous meningitis: a systematic review and meta-analysis. Lancet Infect Dis. 2014 Oct;14(10):947-57. https://doi.org/10.1016/S1473-3099(14)70852-7

40. Kumar K, Giribhattanavar P, Chandrashekar N, Patil S. Correlation of clinical, laboratory and drug susceptibility profiles in 176 patients with culture positive TBM in a tertiary neurocare centre. Diagn Microbiol Infect Dis. 2016 Dec;86(4):372-6. https://doi.org/10.1016/j. diagmicrobio.2016.09.018 